\title{
Calculation of reliability indicators of power supply systems of consumers
}

\author{
S.T. Latipov ${ }^{1 *}$, G.N. Aslanova ${ }^{1}$, L.A. Nematov ${ }^{1}, A . A$. Akhmedov $^{1}$, M.R. Charieva ${ }^{1}$ \\ ${ }^{1}$ Bukhara Engineering-Technological Institute
}

\begin{abstract}
The article covers the study of methods for calculating the reliability of schemes of power supply for consumers at the present stage. It analyzes the existing methods for calculating the reliability of various schemes of power supply systems for consumers. Methods for determining the reliability indicators of redundant systems are reviewed. Examples are given
\end{abstract}

\section{Introduction}

A comprehensive assessment of the reliability of electric power systems (EPS) [1-5, 8-10] includes a joint review of electrical networks (EN), power plants and substations. A lot of publications in Russia [1-5, 8-10] and abroad $[6,7]$ cover the methods of its analysis.

As it is known [3-5], in accordance with accepted terminology, the reliability of power systems (power associations) is understood as their ability to fulfill their main function - continuous power supply of consumers with electricity of the required quality. With a certain convention in the general complex concept of reliability of power systems, functional concepts can be distinguished by particular concepts related to the main structural components of a power system: reliability of a generation system - the property of power plants to maintain the required power balance at a standard frequency value; reliability of the main electric network the property to stably transmit power from parts of the power system with excess power to parts of the power system with a deficit of power; reliability of the distribution network - the property of this network is to provide continuous power to the load nodes.

In the situational aspect, two particular concepts can be distinguished $[9,10]$ : reliability in the steady state (according to the terminology adopted in the USA, adequacy) is the balance reliability, i.e. the ability to balance power and electric energy (EE) with the standard quality of $\mathrm{EE}$; Reliability in the transition process (Security) is the mode reliability, i.e. the ability of individual structural parts and the energy system as a whole to withstand violations of the mode and provide power to consumers.

The reliability of power supply to consumers depends on the reliability of the power system at all its levels, i.e. in power generation, transmission and distribution systems. The reliability of stations, substations, and energy transmission and distribution systems depends on many deterministic and stochastic parameters and, above all, on the structure, as well as the operational safety and recoverability of the main equipment $[1-3,5,10]$.

The task of assessment the reliability of a particular electricity supply option arises at the decision-making stage in the design of new and development of existing systems. The initial information in this case is the scheme and retrospective data on the reliability of its main elements and automation elements. Calculations of the circuit reliability of generating facilities, switchgears, and transmission and distribution systems of electric power have their own specific features, therefore specific methods are oriented to a certain level - a specific class of power system facilities. At the same time, the basis of these calculations consists from general formulas that allow to determine the probabilities, frequencies, and average durations of simultaneous downtime of several elements when their failures coincide, or when a failure of one element is imposed on a scheduled repair of another. These formulas are obtained based on general analytical models $[1-8,10]$.

In the reliability of the electric power industry, two components can be conditionally distinguished $[1-3,5]$ :

1) the first one, due to the structure of the system, i.e. the composition of the elements, their interconnections, throughputs, without a quantitative consideration of the operational features of the functioning of the elements structural reliability;

2) the second one, due to the features of the modes in the system, their limitations on the throughput of the elements when changing the structural system in various states - functional reliability.

Such a subdivision is conditional, because the interconnection of these components is obvious, but it allows simplifying the tasks of assessing the reliability of networks of complex structure.

Currently, reliability requirements are accounted in accordance with regulatory guidelines in directive materials for the design and operation of power systems. The complexity of modern energy facilities and the processes of their functioning, the insufficient accuracy

Corresponding author: zhalilov.rashid@mail.ru 
of the source information, increasing with the increase in the lead-time for the formation of decisions, the need to develop mass solutions determines the feasibility of the predominant application of the normative approach.

An example of the feasibility of using standards in the development of mass solutions is the establishment of standards for the technological design of typical circuits for switchgear of power plants and substations The analysis showed that at present it is recommended to distinguish between two methods of normalizing reliability $[2-6,9,10]$ :

- establishment of normative quantitative values of indicators characterizing individual properties of reliability;

- "indirect" standardization of reliability levels based on regulatory requirements for the energy system (UES, UES), its individual elements, control systems, means of ensuring reliability, etc.

Direct normalization of reliability indicators is limited by the fact that the work on substantiating the choice of these indicators is not completed and the tested composition of these indicators is not available. At the present stage, "indirect" rationing has gained predominant use.

For non-redundant systems, it is not possible to recovery failed elements during operation; they must be disabled. At the same time, reducing the time of switching and recovering failed elements increases the availability of the system, but practically does not affect its reliability.

If the system has redundancy, then recovery is an effective way to increase reliability. By duplicating the functions of the recovered elements and reducing the recovery time, an arbitrarily high degree of system reliability can be achieved.

\section{Determination of system reliability indicators}

The features of redundant systems with recovery is advisable to consider on the example of two mutually redundant elements 1 and 2, for example, parallel power lines, mutually redundant power transformers in substations, etc. [3, 4, 8, 9].

Parallel connection of lines and other circuits, as well as parallel operation of several units is modeled with a structure with parallel connection of elements. This can be considered a system consisting of $n$ elements or pieces of equipment, if $r$ elements are necessary for normal operation, and $n-r$ elements are backup. The system failure occurs when $m$ elements fail, i.e. while the number of backup elements is the number of failed, the system does not fail. Thus, the failure condition is $-1=n-r$.

Consequently, the probability of a system failure is defined as the probability of coincidence of failures $(n-r+1)$ or $m$ elements. If the failures of one element are independent of the failure of other elements, then the formulas for estimating the probability of failure-free operation or the probability of system failure can be obtained by forming the sum of the products of the probabilities $Q_{i}(t)$ and $P_{i}(t)$ based on the product of $n$ binomials

$$
\begin{gathered}
\quad\left[P_{i}(t)+Q_{i}(t)\right]=1: \\
\prod_{i=1}^{n}\left[P_{i}(t)+Q_{j}(t)\right]=P_{1}(t) P_{2}(t) \ldots P_{n}(t)+ \\
Q_{1}(t) P_{2}(t) \ldots P_{n 1}(t)+Q_{1}(t) Q_{2}(t) \ldots Q_{n}(t)
\end{gathered}
$$

Choosing terms with the value $Q_{j}(t) \geq m$, from this sum, we can form an expression for the probability of failure from them. And choosing the terms with the value $Q_{j}(t)<m$, we can form an expression from them for the probability of failure-free operation of the system with parallel connection of elements.

Under the condition of equal reliability of elements:

$$
\begin{array}{r}
Q(t)=\sum_{k=m}^{n} C_{n}^{k} P^{n-k}(t) Q^{k}(t) ; \\
P(t)=\sum_{k=y}^{n} C_{n}^{k} P^{k}(t) Q^{n-k}(t)
\end{array}
$$

where $\mathrm{C}_{n}^{k}=n ! /[(n-k) ! k !]$.

A system with parallel connection of elements is a redundant system, i.e. failure of one or more elements does not cause system failure. Redundancy is permanent if all elements are in operation and the system does not fail until a certain number of them fail. Redundancy by replacement is a redundancy in which redundant elements are turned on only after automatic shutdown of failed elements. In the energy sector, numerous ABP devices, as well as constantly rotating and hidden reserve of generators, transformers and electric motors carry out redundancy by replacement.

At present, in Russia and abroad, there has already planned a transition to the next generation of digital devices for relay protection and automation (DDRPA) with the integration of the functions of relay protection, measurement and commercial metering of energy efficiency, regulation and control of electrical devices within a single information complex [11]. In almost all countries of the world, the concept of smart electric power grid (Smart Grid) has been adopted as a technological platform for the future electric power industry. The use of intelligent EES technologies (FACTS, power storage devices, power electronics, artificial intelligence systems, information and communication technologies, modern methods of control theory) will fundamentally change the properties of future intelligent EES [13]. This in turn necessitates the feasibility of developing research methods and improving the reliability of consumer EPS. At the same time, it is necessary to take into account the reliability of the technological object and to characterize the events, conditions and processes that determine the conditions for the functioning and development of energy supply systems (ESS). Reliability analysis of the power supply system should be closely related to the study of the reliability of the units and the entire production functioning as part of the technological facility, depending on the properties of the power plant, instrumentation and automation equipment, process automation (components of industrial control systems), as well as technological redundancy [10.11] . 
Based on the foregoing, our research is based on probabilistic methods of calculation using stochastic modeling [10-12].

The probability of a fail-free operation of a system with redundancy is determined by the reliability of not only the elements themselves, but also of circuit breakers, which, when constant redundancy, must disconnect the failed element, and when redundant by replacement, also include the redundant one. If the entire system fails when the disconnecting device fails to disconnect, the probability of failure-free operation of the system with constant redundancy will be

$$
P_{\mathrm{c}}=P_{\mathrm{k}} P_{\mathrm{Od}},
$$

where $P_{0, \mathbb{C}}$ - probability of a failure of operation when disconnecting a failed element; $P_{k}-$ the probability of failure of a group of elements with a multiplicity of redundancy $k$.

When redundancy by replacement, the probability of system failure is determined by the formula for the total probability:

$$
\begin{aligned}
& Q_{\mathrm{C}}=\left(s \mid \mathrm{A}_{1} \mathrm{~A}_{2}\right) P\left(\mathrm{~A}_{1}\right) P\left(\mathrm{~A}_{2}\right)+Q\left(s \mid \overline{\mathrm{A}_{1}} \mathrm{~A}_{2}\right) Q\left(\mathrm{~A}_{1}\right) P\left(\mathrm{~A}_{2}\right)+ \\
& +Q\left(s \mid \mathrm{A}_{1} \overline{\mathrm{A}_{2}}\right) P\left(\mathrm{~A}_{1}\right) Q\left(\mathrm{~A}_{2}\right)+Q\left(s \mid \overline{\mathrm{A}_{1}} \overline{\mathrm{A}_{2}}\right) Q\left(\mathrm{~A}_{1}\right) Q\left(\mathrm{~A}_{2}\right),
\end{aligned}
$$

where $Q\left(S \mid A_{1} A_{2}\right)$ - conditional probability of system failure in the absence of device failures; $Q\left(s \mid \overline{A_{1}} A_{2}\right)-$ the same when disconnecting a failed element; $Q\left(S \mid A_{1} \overline{A_{2}}\right)$ - the same with the failure to turn on the redundancy; $Q\left(s \mid \overline{A_{1}} \overline{A_{2}}\right)$ - the same if the failure to disconnect coincides with the failure to turn on;

$P\left(A_{1}\right), Q\left(A_{1}\right)$ - probability of failure abcence and failure to turn-off; $\left(A_{2}\right), Q\left(A_{2}\right)$ - probability of failure abcence and failure to turn-on.

\section{Examples of calculating the reliability indicators of a power supply system}

Example 1. Consumers of their own needs are supplied from two independent sources according to the circuit shown in Fig. 1.

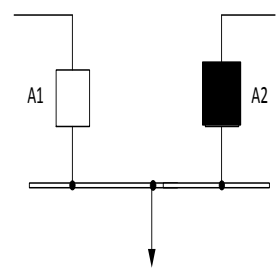

Fig. 1. Supply scheme for consumers of their own needs to two sections



Fig. 2. Connecting consumers
In accordance with the conditions of example примера $Q\left(\mathrm{~A}_{1}\right)-0.05 ; P\left(\mathrm{~A}_{1}\right)=0.95$, one source is turned on constantly, the other is turned on by the action, ABP. The probability of failure of the source during the time between scheduled stops of the unit is 0.90 . The probability of finding a backup source in working condition at any time between scheduled stops is 0.99 . The probability of failure in the shutdown is 0.05 and in the inclusion of 0.01 . To determine the probability of failure-free operation of the power supply system during the time between scheduled turn-off, taking into account the possibility of using a backup source, considering that the probability of its failure during the recovery of a working source can be neglected.

$Q\left(\mathrm{~A}_{2}\right)=0.01 . P\left(\mathrm{~A}_{2}\right)=0.99 . Q\left(s \mid \overline{\mathrm{A}_{1}} \mathrm{~A}_{2}\right)=1$;

$Q\left(s \mid \mathrm{A}_{1} \overline{\mathrm{A}_{2}}\right)=1$.

The probability of a system failure in the absence of device failures is determined by the product of the probability of a working source failure and the probability of backup emergency downtime:

$Q\left(s \mid A_{1} A_{2}\right)=(1-0.9)(1-0.99)=0.1 \cdot 0.01=$ 0.001 .

On equation (5) we have

$Q_{\mathrm{c}}=0.001 \cdot 0.99 \cdot 0.95+1 \cdot 0.05 \cdot 0.99+1 \cdot 0.95$.

$0.01+1 \cdot 0.05 \cdot 0.01=0.06044$

Probability to be determined

$$
P_{\mathrm{c}}=1-0.06044=0.93956 .
$$

Example 2. Consumers of their own needs can be connected to two different sections, powered by two independent sources according to the circuit shown in Fig. 2. The probability of emergency downtime, source failure, and hardware failure are as in the previous example. The difference between the circuits lies in the operation of the switches: the sectional switch provides the ABP of the section left without power due to the neighboring section and its source. We determine the probability of uninterrupted power supply to any of the consumers of this system. According to the terms of the example:

$Q\left(\mathrm{~A}_{1}\right)=2 \cdot 0.05=0.1^{\prime} \quad P\left(\mathrm{~A}_{1}\right)=0.9 ; \quad Q\left(\mathrm{~A}_{2}\right)=0.01_{\text {; }}$ $P\left(A_{2}\right)=0.99$. Each of these consumers may be connected to one of the sections with a probability of 0.5 , therefore $Q\left(s \mid \overline{A_{1}} A_{2}\right)=0.5 ; \quad Q\left(s \mid \overline{A_{1}} \overline{A_{2}}\right)=0.5$; $Q\left(s \mid \mathrm{A}_{1} \overline{\mathrm{A}_{2}}\right)=0.5$.

In the absence of equipment failures, a system failure occurs when the failure of one of the sources coincides with the emergency downtime of another, i.e.

$Q\left(S \mid A_{1} A_{2}\right)=2 \cdot(1-0.9)(1-0.99)=0.002$. On

equation (5) we have

$Q_{\mathrm{c}}=0.002 \cdot 0.9 \cdot 0.99+1 \cdot 0.5 \cdot 0.1 \cdot 0.99+0.5 \cdot 0.9 \cdot$ $0.01=0.05628$.

Probability to be determined 


$$
P_{\mathbb{C}}=1-0.05628=0.94372 .
$$

Example 3. In a case when a consumer is used a complete automatic transformer substation in a PSS, developed by the author [11,12]. We determine the probability of uninterrupted power supply to any of the consumers of this system

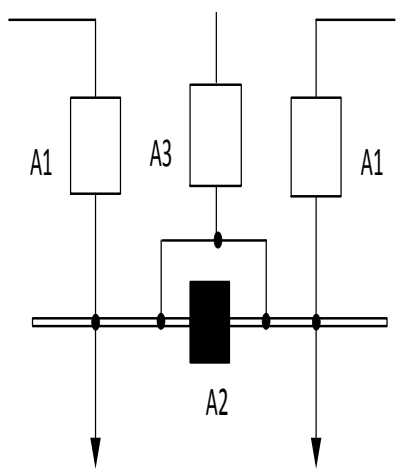

Fig. 3. Consumer supply according to the scheme from $\mathrm{ABP}$ to $\mathrm{CB}$ and implementation of the $3^{\text {rd }}$ independent source with automatic reverse transition.

In the absence of failures of the switches of the two main inputs, the failure of the system occurs when the failure of one of the sources coincides with the emergency downtime of the other, i.e.

$Q\left(s \mid A_{1} A_{2}\right)=3 \cdot(1-0.85)(1-0.99)=0.0045$.

Conditional probability of failure of the $3^{\text {rd }}$ independent source

$Q\left(S \mid A_{1} A_{2} \overline{A_{2}}\right)-=2 \cdot(0.5 \cdot 0.9) \cdot 0.01-3 \cdot 0.01=$ 0.039

On equation (5) we have

$Q_{\mathrm{C}}=0.0045 \cdot 0.85 \times 0.99+0.5 \times 0.1 \times 0.99+0.5 \times 0.9$.

$0.01+0.5 \cdot 0.9 \cdot 0.01=0.003787+0.0495+$

$0.0045+0.0045-0.009=0.06229-0.039=$

0.02329 .

Probability to be determined

$P_{\mathbb{C}}=1-0.02329=0.97671$.

\section{Comparative results}

The calculation results and their comparison are presented in the table.
Table. Comparison of reliability indicators of options for power supply schemes

\begin{tabular}{|c|c|c|c|}
\hline \multirow[t]{2}{*}{$\begin{array}{l}\text { Estimated } \\
\text { indicators }\end{array}$} & \multicolumn{2}{|c|}{$\begin{array}{r}\text { Existing } \\
\text { scheme options }\end{array}$} & \multirow{2}{*}{$\begin{array}{l}\text { Designe } \\
\text { d from ABP to } \\
\text { CB and } \\
\text { implementatio } \\
\text { n of the } 3^{\text {rd }} \\
\text { independent } \\
\text { source with } \\
\text { automatic } \\
\text { reverse } \\
\text { transition }\end{array}$} \\
\hline & $\begin{array}{l}\text { with } \\
\text { ABP } \\
\text { on one } \\
\text { of the } \\
\text { inputs }\end{array}$ & $\begin{array}{c}\text { with } A B P \\
\text { on } C B\end{array}$ & \\
\hline$Q\left(A_{1}\right)$ & 0.05 & 0.1 & 0.15 \\
\hline$P\left(A_{1}\right)$ & 0.95 & 0.9 & 0.85 \\
\hline$Q\left(A_{2}\right)$ & 0.01 & 0.01 & 0.01 \\
\hline$P\left(A_{2}\right)$ & 0.99 & 0.99 & 0.99 \\
\hline$Q\left(s \mid \overline{A_{1}} A_{2}\right)$ & 1 & 0.5 & 0.5 \\
\hline$Q\left(S \mid \overrightarrow{A_{1}} \overrightarrow{A_{2}}\right)$ & 1 & 0.5 & 0.5 \\
\hline$Q\left(s \mid A_{1} \overline{A_{2}}\right)$ & 1 & 0.5 & 0.5 \\
\hline$Q\left(S \mid A_{1} A_{2}\right)$ & 0.001 & 0.002 & 0.003 \\
\hline$Q\left(S \mid A_{1} A_{2} A_{2}\right)$ & - & - & 0.039 \\
\hline$Q_{\mathrm{c}}$ & $\begin{array}{c}0.060 \\
44\end{array}$ & 0.05628 & 0.02329 \\
\hline$P_{\mathrm{C}}$ & $\begin{array}{c}0.939 \\
56\end{array}$ & 0.94372 & 0.97671 \\
\hline
\end{tabular}

The use of a circuit with constant redundancy and ABP on a sectional switch increases the probability of continuous power supply to consumers. In addition, partitioning reduces the probability of a complete loss of power to all consumers. Without sectioning, failure of the switch of any of the connections leads to complete extinction, and during sectioning, to the disconnection of only one of the sections, i.e. to discharge half of consumers. The application of the ABP scheme at the $\mathrm{CB}$ and the implementation of the $3^{\text {rd }}$ independent source with automatic reverse switching to supply from the main inputs is the most maneuverable and even more increases the probability of uninterrupted power supply to consumers. The probability of failure of the power supply system during the time between scheduled stops, taking into account the possibility of using a backup source, is high and the probability of its failure during the restoration of the working source is not high.

\section{Conclusion}

1. One of the main ways to improve the efficiency of methods and programs for assessing the reliability of ESS is to automatically select significant and ordered failures of not only power equipment, but also DDRPA devices, instrumentation and automation equipment, technological automation (components of industrial control systems), as well as devices and complexes of technological redundancy of consumers.

2. To improve the methods of analyzing the reliability of EPS, it is necessary to develop methods, algorithms, and software for the comprehensive assessment of the reliability of electric power plants and power systems, distribution and transmitting electric power systems, devices of central distribution and 
automation systems, DDRPA and TM, as well as assessing the level of safety and survivability of EPS.

\section{References}

1. Voropay N.I., Domyshev A.V., Nepomnyashchy V.A. Models and methods for research the operational reliability of electric power systems // Reliability of energy systems: Problems, models and methods for solving them. Novosibirsk: Nauka, 2014, p. 57-73.

2. V.A. Ovseychuk, V.A. Nepomnyashchy. Rationing of reliability and quality of power supply to consumers // Innovation and Expertise. 2016. Issue 1/16. p.178-185. [Electronic resource] .URL: http: // www. energystrategy. com / projects / energy_21.htm (date of application: 04/20/2019).

3. Kitushin. Reliability of energy systems. Part 1. Theoretical basis: Textbook.-Novosibirsk: Publishing House of NSTU.-2003.p. 256.

4. Guk B.Yu. The theory of reliability in the electric power industry. - Moscow: Energoatomizdat. Leningrad branch, 1990 . p.207.

5. GOST 27.301-95. Reliability in technology. Reliability calculation. Key Points. - Moscow: Publishing House of Standards, 1995.
6. Endreni, J. Modeling in reliability calculations in electric power systems: Translated from English / Ed. Yu.N. Rudenko. M .: Energoatomizdat, 1983.

7. Billinton R., Allan R. N. Reliability evalition of Power Systems. -New York, 1984.

8. Menshov B.G., Ershov M.S. Reliability of power supply systems of compressor stations. - M : Nedra, 1995.

9. Savina N.V. The theory of reliability in the electric power industry. Amur State University Blagoveshchensk, 2007. p.228.

10. Jalilov R.B., Sitdikov R.A. A systematic approach to ensuring the reliability of operation of electric power systems // Problems of energy and resource saving, Tashkent, 2016. No. 3-4, p. 127-132.

11. Jalilov R.B. A new approach to the creation of an intelligent automated substation // Industrial Energy, 2008. No. 4, p.15-18.

12. Jalilov RB Complete automatic transformer substation. Patent of Republic of Uzbekistan for useful model No. FAP 01303. 04/27/2018.

13. Voropai N.I., Efimov D.N., Kurbatsky V.G., Panasetskiy D.A., Tomin N.V. Algorithms of survivability and self-recovery of intelligent electric power systems // [Electronic resource]. URL: http: // www.energystrategy.ru/ projects / -energy_21.htm (date of application: 04/20/2019). 